\title{
Serum Lipid Profile: A cellular signature in occurrence and progression of potentially malignant disorders and oral cancer
}

\author{
Rashmi K ${ }^{1, *}$, Vathsala Naik ${ }^{2}$, Raghavendra Kini ${ }^{3}$, Stuti Goyal ${ }^{4}$ \\ ${ }^{\mathbf{1}, \mathbf{4}}$ Senior Lecturer, ${ }^{2}$ Professor \& HOD, ${ }^{3}$ Professor \& Vice Principal, Dept. of Oral Medicine and Radiology, ${ }^{\mathbf{1 , 4}}$ Srinivas Institute of \\ Dental Sciences, Mangaluru, Karnataka, ${ }^{2}$ Bangalore Institute of Dental Sciences, Bengaluru, Karnataka, ${ }^{3}$ AJ institute of Dental \\ Sciences, Mangaluru, Karnataka, India
}

*Corresponding Author:

Email: Rashmi_mang@yahoo.co.in

\begin{abstract}
Introduction and objectives: Serum lipid profile is used to measure the systemic health status of an individual. The objective of the study was to evaluate and correlate serum lipid profile in patients with potentially malignant disorders, oral cancer and controls.

Materials and Methods: This study was conducted on a sample of 150 subjects in which the subjects were divided into three groups with 50 subjects in each group. The subjects in Group I were Controls (CT) Group II were Potentially Malignant Disorder (PMD) and Group III were Oral Cancer (OC). Out of 150 subjects 50 subjects were diagnosed as potentially malignant disorder and 50 were diagnosed as oral cancer based on histopathological diagnosis.

Results: When results of group III were compared and correlated to subjects of group I, a decrease in TC, HDL, LDL and VLDL was elicited. When results of group II were compared and correlated to subjects of group I, a decrease in TC, HDL, LDL and VLDL was elicited. Triglycerides, was not significantly altered in the study.

Interpretation and Conclusion: The results of our study showed an evidence of an inverse relationship between serum lipid profile and oral cancer and potentially malignant disorders. The lower serum lipid status may be considered as an indicator to reflect the initial changes occurring in neoplastic cells, thus substantiating their use as a diagnostic adjuvant in monitoring the oral cancer and potentially malignant disorder.
\end{abstract}

Keywords: Blood (serum), Potentially Malignant Disorder, Oral Cancer, Serum Lipid Profile.

\section{Introduction}

Oral cancer(OC) is one of the most prevalent cancer and is one of the six most common causes of death worldwide. ${ }^{1}$ In India, it is estimated that there are 2 to 2.5 million cancer patients with about 0.7 million new cases diagnosed every year. Potentially malignant disorders (PMD) is defined by the World Health Organization as a morphologically altered tissue in which cancer is more likely to occur. ${ }^{1}$ Based on the frequency of occurrence and its subsequent malignant potential, Leukoplakia, Erythroplakia, Oral submucous fibrosis (OSMF), and Lichen Planus(LP) is ranked higher among the other potentially malignant disorders.

Oral cancer mostly occurs as a result of malignant transformation of pre-existing potentially malignant disorder. As documented, the phenotypic changes of oral cancer are always preceded by genetic damages accumulated due to various carcinogens. Early detection of dysplastic lesion leading to malignancy is a continuing goal. Among them the idea of screening the patients with cancer, by blood-based tests are appealing from several points of view, including its ease, economic advantage, and possibility of repeated sampling. One such method is that profiling of a serum lipid status, which may be a useful indicator for initial changes occurring in neoplastic cells. ${ }^{2}$

Lipids form a major cell membrane component and are essential for various biological functions including cell division and growth. Therefore there is a greater utilization of lipids including total cholesterol, lipoproteins and triglycerides for new membrane biogenesis. Three main hypotheses ${ }^{2}$ which explain the inverse association between cholesterol concentration and incidence of cancer are;

First, lower cholesterol value seen, even before the manifestation or detection of the cancer, may be a result of cancer process.

Second, lower cholesterol values may precede the development of cancer, but the association with cancer is secondary, which indicates that cholesterol serves as a marker for some other causal variable or set of variables.

Third, lower cholesterol values may precede the development of cancer and may be casually associated with the occurrence of cancer.

Hence the present study was designed to evaluate lipid profile not only in oral cancer patients, but also in the potentially malignant disorders of patients in comparison with normal healthy individuals.

\section{Materials and Methods}

After obtaining the informed consent, data and blood samples were collected from the patients visiting the Department of Oral Medicine and Radiology, A.J. Institute of Dental Sciences, Mangalore. The subjects were studied in the following age, sex and socioeconomic status matched groups with 50 patients each. Group1: 50 Normal individuals as Control group (CT). 
Group2: 50 Patients with potentially malignant disorders (PMD).

Group 3:50 Patients with oral cancer (OC).

The subjects with history of dyslipidemia, undergoing treatment or on medication for potentially malignant disorders and oral cancer, lipid metabolism disorders, uncontrolled diabetes mellitus, thyroid disorder and liver dysfunction were excluded from the study. The subjects who were clinically and histopathologically diagnosed with potentially malignant disorders and oral cancer were included in the PMD and OC group respectively. Normal healthy subjects without any systemic diseases were included in the CT group. About $5 \mathrm{ml}$ of fasting (12-14h) blood samples was collected in a plain sterile vaccutainer and allowed to clot for about half hour at room temperature. Sample was centrifuged for 5 minutes at 4000 revolution per minute(rpm).The serum was separated and stored at $4^{\circ} \mathrm{C}$. The serum lipid profile [consisting of Total Cholesterol (TC), Triglycerides (TG), High Density Lipoprotein (HDL), Low Density Lipoprotein (LDL), Very Low Density Lipoprotein (VLDL)] was carried out using Cholesterol Kit (CHOD-PAP) obtained from RFCL Limited (Dehradun, Uttarakhand), and Triglycerides Kit (GPO-ESPAS) obtained from RCFL Limited(Dehradun, Uttarakhand). The normal range of serum lipid profile parameters $(\mathrm{mg} / \mathrm{dl})$ considered for the study male and female are TC as $150-200 \mathrm{mg} / \mathrm{dl}$, TG as 40-150 mg/dl, LDL as 60$130 \mathrm{mg} / \mathrm{dl}$, VLDL as $0-40 \mathrm{mg} / \mathrm{dl}$ and HDL for males as $35-55 \mathrm{mg} / \mathrm{dl} \&$ for females as $45-65 \mathrm{mg} / \mathrm{dl}$ respectively. After obtaining the data, it was tabulated and statistical analysis was performed (ANOVA, Tukeys, $\mathrm{X}^{2}$ test).

\section{Results}

Group I (CT) consisted of 50 individuals with minimum age of 17 years and maximum age of 75 years. The mean value was 41.36 with a standard deviation of 15.798.Group II PMD consisted of 50 individuals with minimum age of 20 years and maximum age of 73 years. The mean value was 40.46 with a standard deviation of 14.735. Group III OC consisted of 50 individuals with minimum age of 17 years and maximum age of 72 years. The mean value was 51.42 with a standard deviation of 10.7999 . Statistical analysis showed $\mathrm{p}<0.001$ very highly significant (vhs).

Group I (CT) out of 50 subjects $29(58.0 \%)$ were males and $21(42.0 \%)$ female, Group II (PMD) out of 50 subjects $37(74.0 \%)$ male and $13(26.0 \%)$ female , Out of 50 subjects from Group III (OC) 34(68.0\%) male and $16(32.0 \%)$ females. Pearson Chi-Square $\left(\mathrm{x}^{2}\right)$ value was 2.94 with $\mathrm{p}<0.23$, which was non significant (ns).

Correlation of TC was done according to histopathological grading in PMD which includes Leukoplakia as mild, moderate and severe epithelial dysplasia, OSMF with epithelial dysplasia and LP. Out of 50 subjects, 10 subjects showed mild epithelial dysplasia, 5 moderate and 1 severe dysplasia, 23 subjects were histopathologically diagnosed with OSMF and 4 subjects with LP, 7 subjects diagnosed as OSMF with epithelial dysplasia. Pearson Chi-Square $\left(\mathrm{x}^{2}\right)$ value was $\mathrm{X}^{2}=17.441, \mathrm{p}<0.134$ which is non significant (ns).

Correlation of TC was done according to histopathological grading in Oral cancer which is further grouped as moderately differentiated SCC, well differentiated SCC, and poorly differentiated SCC. Out of 50 subjects, 24 subjects were moderately differentiated, 25 well differentiated, and 1 poorly differentiated SCC. Total cholesterol in all the groups was non-significant. Pearson Chi-Square $\left(\mathrm{x}^{2}\right)$ value was $\mathrm{X}^{2}=7.594, \mathrm{p}<0.134$ (ns).

Serum TC was estimated by using agappe method among all the three groups. TC among Group I (CT) out of 50 subjects, $3(6.0 \%)$ subjects were below normal, 21(42.0\%) subjects showed normal TC and $26(52.0 \%)$ subjects were above normal TC. TC among Group II (PMD) out of 50 subjects, 21(42.0\%) subjects were below normal TC, 20(40.0\%) subjects showed normal TC and 9(18.0\%) subjects levels were above normal TC. TC among Group III (OC) out of 50 subjects, $22(44.0 \%)$ subjects showed below normal TC, $18(36.0 \%)$ subjects were with normal TC and 10 $(20.0 \%)$ showed above normal TC. Pearson Chi-Square $\left(\mathrm{x}^{2}\right)$ value was 27.284 and all the three subjects showed very high significant (vhs) results with $\mathrm{p}<0.001$. (Table 1)

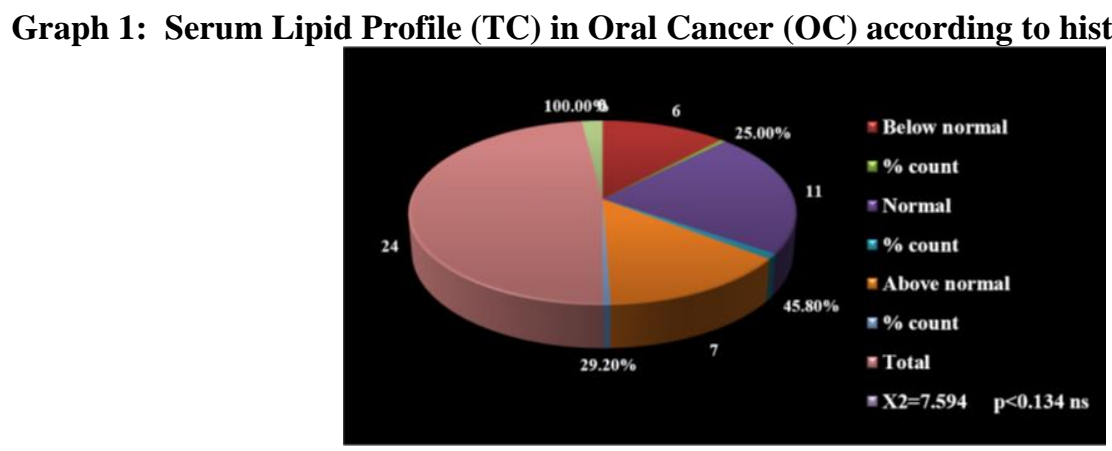


Table 1: Total Cholesterol (TC) levels among three groups

\begin{tabular}{|l|c|c|c|c|}
\hline $\begin{array}{l}\text { Total } \\
\text { Cholesterol (TC) }\end{array}$ & \multicolumn{3}{|c|}{ Group } & Total \\
\hline & CT & PMD & OC & \\
\hline Below normal & 3 & 21 & 22 & 46 \\
\% count & $6.0 \%$ & $42.0 \%$ & $44.0 \%$ & $30.7 \%$ \\
\hline Normal & 21 & 20 & 18 & 59 \\
\% count & $42.0 \%$ & $40.0 \%$ & $36.0 \%$ & $39.3 \%$ \\
\hline Above normal & 26 & 9 & 10 & 45 \\
\% count & $52.0 \%$ & $18.0 \%$ & $20.0 \%$ & $30.0 \%$ \\
\hline Total cal & 50 & 50 & 50 & 150 \\
\% count & $100 \%$ & $100 \%$ & $100 \%$ & $100 \%$ \\
\hline $\mathbf{X}^{2}=\mathbf{2 7 . 2 8 4}$ p $\mathbf{0 . 0 0 1}$ vhs \\
\hline
\end{tabular}

HDL among Group I(CT) out of 50 subjects, 1(2.0\%) subjects were below normal.30(60.0\%) subjects showed normal HDL and 19(38.0\%) subjects showed above normal HDL. HDL among Group II (PMD) out of 50 subjects, $13(26.0 \%)$ subjects showed below normal HDL, 30(60.0\%) subjects showed normal HDL and 7(14.0\%.) subjects were above normal HDL. HDL among Group III (OC) out of 50 subjects, 30(60.0\%) subjects were below normal HDL, 18(36.0\%) subjects showed normal HDL and 2(4.0\%.) subjects were above normal HDL. Pearson Chi-Square $\left(\mathrm{x}^{2}\right)$ value was $\mathrm{x}^{2}=49.004$ and $\mathrm{p}<0.001$ (vhs). (Table 2 )

Graph 2: Total Cholesterol (TC) levels among three groups

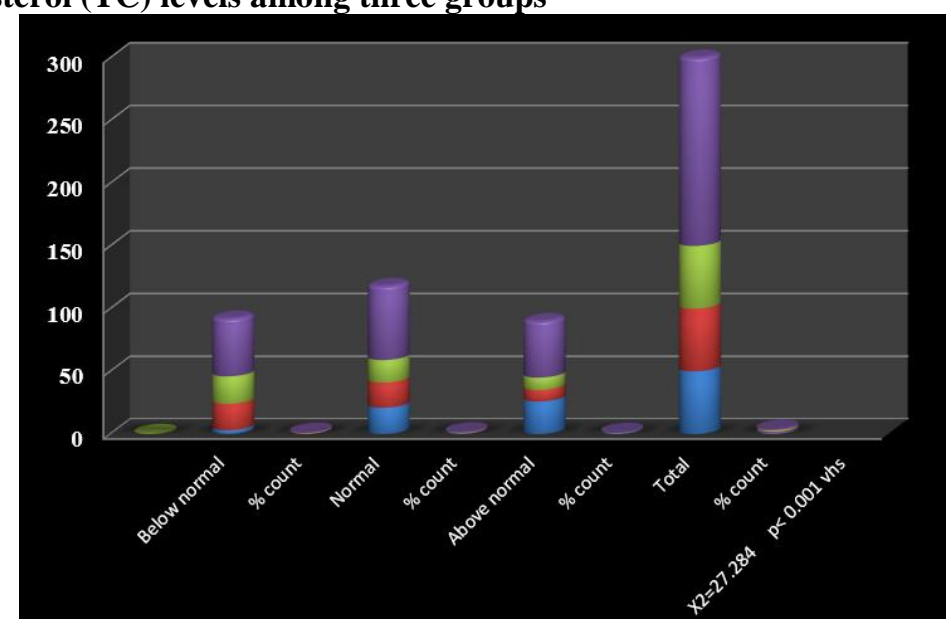

Table 2: High Density Lipoprotein (HDL) levels among three groups

\begin{tabular}{|c|c|c|c|c|}
\hline \multirow[t]{2}{*}{ HDL } & \multicolumn{3}{|c|}{ Group } & \multirow[t]{2}{*}{ Total } \\
\hline & CT & PMD & OC & \\
\hline $\begin{array}{l}\text { Below normal } \\
\% \text { count }\end{array}$ & $\begin{array}{c}1 \\
2.0 \%\end{array}$ & $\begin{array}{c}13 \\
26.0 \%\end{array}$ & $\begin{array}{c}30 \\
60.0 \%\end{array}$ & $\begin{array}{c}44 \\
29.3 \%\end{array}$ \\
\hline $\begin{array}{l}\text { Normal } \\
\% \text { count }\end{array}$ & $\begin{array}{c}30 \\
60.0 \%\end{array}$ & $\begin{array}{c}30 \\
60.0 \%\end{array}$ & $\begin{array}{c}18 \\
36.0 \%\end{array}$ & $\begin{array}{c}52 \\
78.0 \%\end{array}$ \\
\hline $\begin{array}{l}\text { Above normal } \\
\% \text { count }\end{array}$ & $\begin{array}{c}19 \\
38.0 \%\end{array}$ & $\begin{array}{c}7 \\
14.0 \%\end{array}$ & $\begin{array}{c}2 \\
4.0 \%\end{array}$ & $\begin{array}{c}28 \\
18.7 \%\end{array}$ \\
\hline Total & $\begin{array}{c}50 \\
100.0 \% \\
\end{array}$ & $\begin{array}{c}50 \\
100.0 \% \\
\end{array}$ & $\begin{array}{c}50 \\
100.0 \% \\
\end{array}$ & $\begin{array}{c}150 \\
100.0 \% \\
\end{array}$ \\
\hline
\end{tabular}

VLDL among Group I(CT) out of 50 subjects, 43(86.0\%) subjects were below normal, 7(14.0\%) subjects showed normal VLDL.VLDL among Group II (PMD) out of 50 subjects, 49(98.0\%) subjects were below normal VLDL, 1(2.0\%) subject showed normal VLDL .VLDL among Group III (OC) out of 50 subjects, 48(96.0\%) subjects were below normal VLDL, 2(4.0\%) subjects showed normal VLDL. Pearson Chi-Square $\left(\mathrm{x}^{2}\right)$ value was $\mathrm{x}^{2}=6.643$ and $\mathrm{p}<0.036(\mathrm{sig})$. (Table 3) 
Graph 3: High Density Lipoprotein (HDL) levels among three groups

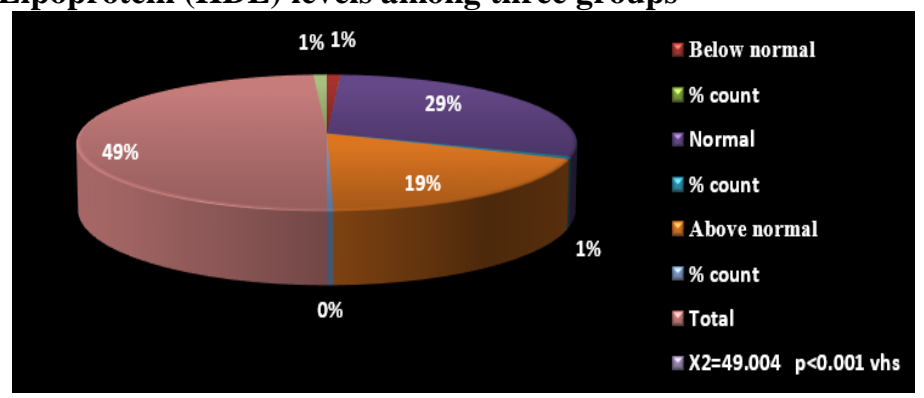

Table 3: Very Low Density Lipoprotein (VLDL) levels among three groups

\begin{tabular}{|l|c|c|c|c|}
\hline \multirow{2}{*}{ VLDL } & \multicolumn{3}{|c|}{ Group } & \multirow{2}{*}{ Total } \\
\cline { 2 - 4 } $\begin{array}{l}\text { Below normal } \\
\text { \% count }\end{array}$ & $\begin{array}{c}43 \\
86.0 \%\end{array}$ & $\begin{array}{c}49 \\
98.0 \%\end{array}$ & $\begin{array}{c}48 \\
96.0 \%\end{array}$ & $\begin{array}{c}140 \\
93.3 \%\end{array}$ \\
\hline $\begin{array}{l}\text { Normal } \\
\text { \% cont }\end{array}$ & 7 & 1 & 2 & 10 \\
\hline Total & $14.0 \%$ & $2.0 \%$ & $4.0 \%$ & $6.7 \%$ \\
\hline & 50 & 50 & 50 & 150 \\
$\mathrm{X}^{2}=6.643 \quad \mathrm{p}<0.036(\mathrm{sig})$ & $100.0 \%$ & $100.0 \%$ & $100.0 \%$ \\
\hline
\end{tabular}

TG among Group I (CT) out of 50 subjects, 39(78.0\%) subjects showed normal TG, 11 (22.0\%) subjects showed above normal TG. TG among Group II (PMD) out of 50 subjects, 43(86.0\%) subjects showed normal TG, 7 (14.0\%) subjects showed above normal TG. TG among Group III (OC) out of 50 subjects, 45(90.0\%) subjects were below normal VLDL, 5(10.0\%) subjects showed above normal VLDL. Pearson Chi-Square $\left(\mathrm{x}^{2}\right)$ value was $\mathrm{X}^{2}=2.876, \mathrm{p}<0.237$ which is non significant (ns). (Table 4)

Graph 4: Very Low Density Lipoprotein (VLDL) levels among three groups

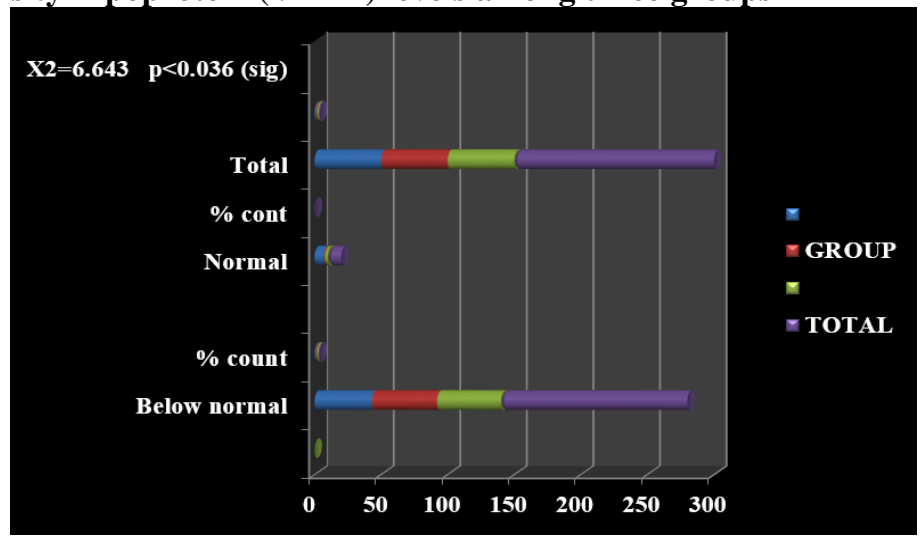

Table 4: Triglycerides (TG) levels among three groups

\begin{tabular}{|l|c|c|c|c|}
\hline \multirow{2}{*}{$\begin{array}{l}\text { Triglycerides } \\
\text { TG) }\end{array}$} & \multicolumn{3}{|c|}{ Group } & \multirow{2}{*}{ Total } \\
\cline { 2 - 4 } $\begin{array}{l}\text { Normal } \\
\text { \% count }\end{array}$ & 39 & 43 & 45 & 127 \\
\hline $\begin{array}{l}\text { Above normal } \\
\text { \% count }\end{array}$ & 11 & 7 & 5 & 23 \\
\hline TOTAL & $22.0 \%$ & $14.0 \%$ & $10.0 \%$ & $15.3 \%$ \\
\% count & 50 & 50 & 50 & 150 \\
\hline $\mathrm{X}^{2}=2.876 \quad \mathrm{p}=0.237(\mathrm{~ns})$ & $100.0 \%$ & $100.0 \%$ & $100.0 \%$ \\
\hline
\end{tabular}

LDL estimation of Group I (CT) out of 50 subjects, No (0\%) subjects were below normal, 28(56.0\%) subjects showed normal LDL and 22(44.0\%) subjects were above normal LDL. LDL among Group II (PMD) out of 50 
subjects, 3(6.0\%) subjects were below normal LDL, 39(78.0\%) subjects showed normal LDL and 8 (16.0\%) subjects were above normal LDL. LDL among Group III (OC) out of 50 subjects, $2(4.0 \%)$ subjects showed below normal LDL, 38(76.0\%) subjects were with normal LDL and 10(20.0\%) showed above normal LDL. Pearson ChiSquare $\left(\mathrm{x}^{2}\right)$ value was $\mathrm{x}^{2}=13.514$ and $\mathrm{p}<0.009(\mathrm{hs})$. (Table 5)

\section{Graph 5: Triglycerides (TG) levels among three groups.}

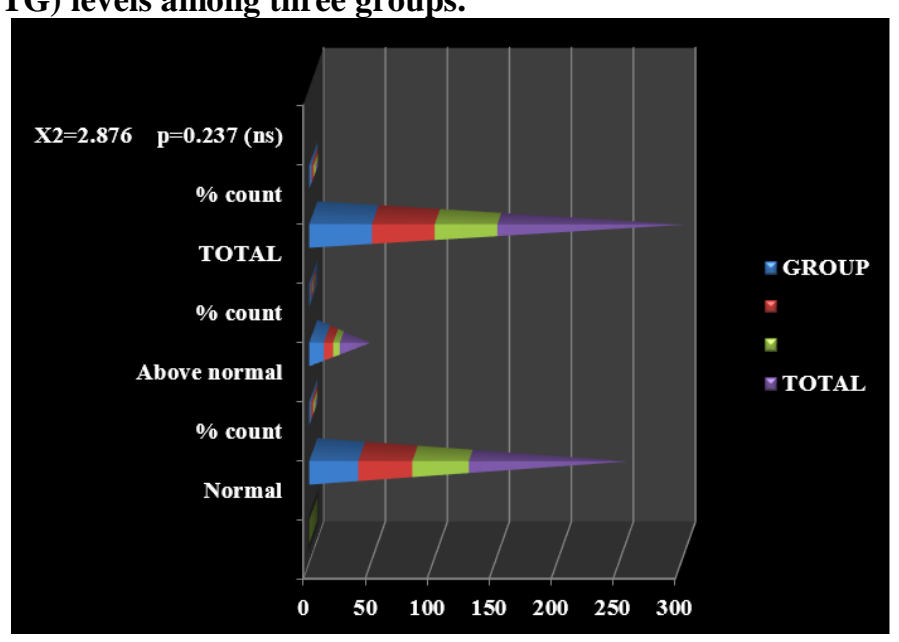

Table 5: Low density lipoproteins (LDL) levels among three groups

\begin{tabular}{|l|c|c|c|c|}
\hline \multirow{2}{*}{ LDL } & \multicolumn{3}{|c|}{ Group } & \multirow{2}{*}{ Total } \\
\cline { 2 - 5 } & CT & PMD & OC & \\
\hline Below normal & 0 & 3 & 2 & 5 \\
$\%$ count & $0 \%$ & $6.0 \%$ & $4.0 \%$ & $3.3 \%$ \\
\hline Normal & 28 & 39 & 38 & 105 \\
$\%$ count & $56.0 \%$ & $78.0 \%$ & $76.0 \%$ & $70.0 \%$ \\
\hline Above normal & 22 & 8 & 10 & 40 \\
$\%$ count & $44.0 \%$ & $16.0 \%$ & $20.0 \%$ & $26.7 \%$ \\
\hline Total & 50 & 50 & 50 & 150 \\
$\%$ count & $100.0 \%$ & $100.0 \%$ & $100.0 \%$ & $100.0 \%$ \\
\hline $\mathrm{X}^{2}=13.514$ & $\mathrm{p}<0.009 \mathrm{hs}$ \\
\hline
\end{tabular}

TC among Group I(CT) had mean value of 202.960 with Std. Deviation of 35.927.TC among Group II (PMD) mean value of 163.340 and Std. Deviation of 40.976 and Group III(OC) showed mean value of 163.960 and Std.Deviation of 37.241.Above three groups showed frequency of total cholesterol as 17.738 and $\mathrm{p}<0.001$ was very highly significant (vhs). LDL among Group I (CT) showed mean value of 128.152 and Std. Deviation of 33.528, Group II(PMD) with mean value of 108.640 and Std. Deviation of 29.768 and Group III(OC) subjects showed mean value of 102.236 and Std. Deviation of 29.370. The frequency for LDL was 9.515 with $p$ value of $p<0.001$ very high significant (vhs). HDL among Group I (CT) showed mean value of 52.020 and Std. Deviation of 12.228, Group II(PMD) with mean value of 43.260 and Std. Deviation of 10.898 and Group III(OC) subjects showed mean value of 35.580 and Std. Deviation of 9.647. All the three group showed frequency of HDL of 28.088 with p<0.001very high significant (vhs). VLDL among Group I (CT) mean value of 25.286 and Std. Deviation of 12.302, VLDL among Group II(PMD) with mean value of 20.411 and Std. Deviation of 7.455 and Group III(OC) subjects showed mean value 23.920 and Std. Deviation of 10.666. All the three group showed frequency of VLDL as 2.958 with p<0.05 significant results (sig). (Table 6) 
Graph 6: Low density lipoproteins (LDL) levels among three groups

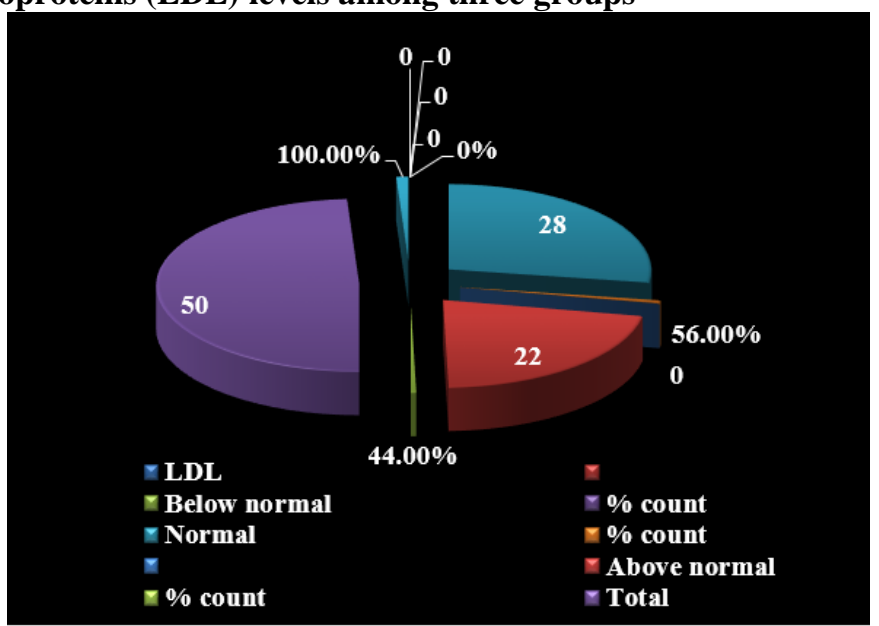

Table 6: Co-Relation of Serum Lipid Profile (TC, LDL, HDL, VLDL) levels among three groups group

\begin{tabular}{|c|c|c|c|c|c|c|}
\hline $\begin{array}{c}\text { Serum lipid } \\
\text { profile }\end{array}$ & Subjects & $\mathbf{N}$ & Mean & Std. Deviation & $\mathbf{F}$ & $\mathbf{P}$ \\
\hline \multirow[t]{3}{*}{ TC } & CT & 50 & 202.960 & 35.927 & \multirow[t]{3}{*}{17.738} & \multirow[t]{3}{*}{$<0.001$ vhs } \\
\hline & PMD & 50 & 163.340 & 40.976 & & \\
\hline & OC & 50 & 163.960 & 37.241 & & \\
\hline \multirow[t]{3}{*}{ LDL } & CT & 50 & 128.152 & 33.528 & \multirow[t]{3}{*}{9.515} & \multirow[t]{3}{*}{$<0.001 \mathrm{vhs}$} \\
\hline & PMD & 50 & 108.640 & 29.768 & & \\
\hline & OC & 50 & 102.236 & 29.370 & & \\
\hline \multirow[t]{3}{*}{ HDL } & CT & 50 & 52.020 & 12.228 & \multirow[t]{3}{*}{28.088} & \multirow[t]{3}{*}{$<0.001 \mathrm{vhs}$} \\
\hline & PMD & 50 & 43.260 & 10.898 & & \\
\hline & OC & 50 & 35.580 & 9.647 & & \\
\hline \multirow[t]{3}{*}{ VLDL } & CT & 50 & 25.286 & 12.302 & \multirow[t]{3}{*}{2.958} & \multirow[t]{3}{*}{$0.05 \mathrm{sig}$} \\
\hline & PMD & 50 & 20.411 & 7.455 & & \\
\hline & OC & 50 & 23.920 & 10.666 & & \\
\hline
\end{tabular}

When compared and correlated to subjects of group 1 with group 3, results showed decrease in TC, HDL, LDL, VLDL and triglycerides showing no significant. When compared and correlated to subjects of group 1 with group 2, results showed decrease in TC, HDL, LDL. VLDL, and when compared to group 3 with group 2 showed decreased TC, HDL, LDL, VLDL. On histological analysis, no correlation was found between mean serum lipid profiles and degree of dysplasia in potentially malignant disorder, degree of differentiation in oral cancer group.

To summarize, our results add to the evidence of inverse relationship between lower serum lipid profile and oral cancer, potentially malignant disorders.

\section{Discussion}

Head and neck cancer accounts for $30-40 \%$ of all malignant tumors in India and the most common malignant neoplasm is Oral Squamous Cell Carcinoma (OSCC). ${ }^{3}$ PMD plays a crucial role in pathogenesis of Squamous cell carcinoma in the oral cavity. The risk of neoplastic transformation of PMDs varies from $0.3 \%$ to $2.5 \% .^{2}$ Thus, the development of newer diagnostic and predictive approaches that are safe, economical, and amenable to repeated sampling is imperative. Bloodbased/serum-based tests offer the aforementioned advantages, serum total cholesterol being one among them. Lower levels of serum cholesterol causes cell membrane alterations thereby causing increased membrane permeability to carcinogens. These carcinogens induce generation of free reactive oxygen radical species, which are responsible for high rate of oxidation / peroxidation of polyunsaturated fatty acids of cell membrane causing cell membrane disruption. Consequent to this there would be increased neo membrane genesis needing a greater utilization of lipids including total cholesterol, lipoproteins and triglycerides. This increased need is met either from, stored lipid depots, increased lipid metabolism or from degradation of major lipoprotein fractions, thereby causing decrease in the serum cholesterol levels.

The present study showed peak age incidence of patients were in the age range of 40-60yrs in both potentially malignant disorder and oral cancer, which is in accordance with observations reported by Mashberg And Silverman ${ }^{4}$ This age related incidence suggest that the time dependent factors results in the initiation and promotion of genetic events that result in malignant 
changes and the diminished immune surveillance seen in the older age group.

The present study, showed male predominance in gender predilection among all the groups studied. The lesions were more prevalent among males than females. This difference may be due to the fact that a large number of men were reported with the history of habits (smoking, chewing tobacco). Though this observation was not statistically significant. This was in accordance to the study conducted by Goyal $\mathrm{S}$ et al. ${ }^{5}$

The oral cancer (OC) group was studied histologically and graded into well differentiated, moderately differentiated and poorly differentiated carcinoma according to degree of differentiation. Krontiras and Roye stated that the differential utilization of serum lipid by malignant cells can be explained by the fact that the enzyme fatty acid synthase which is necessary for the synthesis of fatty acid increases as the differentiation of the cell decreases. The enzyme fatty acid synthase and its activity is highly elevated in biosynthetically altered anaplastic cells of poorly differentiated lesions as compared to moderate and well differentiated lesions. ${ }^{6}$ However in contrary to afore mentioned statement, we observed the mean serum lipid parameters TC, TG, HDL, LDL, VLDL, showed no significant $p$ value according to degree of differentiation. Similar findings were also obtained in the studies by Jyothi Chawda et al., ${ }^{7}$ Kumar P et al. ${ }^{8}$ and Anuradha et al. ${ }^{9}$

In the present study, the serum lipid profile parameters like TC, HDL and VLDL showed lower values in PMD and OC groups when compared to control group. TG and LDL showed no significant changes. The results obtained in our study are on par with the results of Jyothi Chawda et al., ${ }^{7}$ Sherubin EJ et al., ${ }^{6}$ Patel PS et al., ${ }^{10}$ Mehrotra R et al., ${ }^{11}$ Lohe V et al. ${ }^{12}$ and Nayak $\mathrm{P}$ et al. ${ }^{13}$ and disagreed with the results of Goyal S et al. ${ }^{5}$

Our results add to the evidence of inverse relationship between lower serum lipid profile in oral cancer and potentially malignant disorders. Although the role of tobacco has been established as an etiological factor for oral cancer and potentially malignant disorders, it may have an indirect and overall significant association with serum lipid profile.

\section{Conclusion}

Serum lipid profile is used to measure the systemic health status of an individual. Nevertheless it also depicts the other side of the oral health in individuals affected by potentially malignant and oral cancer with the habit of tobacco in various forms. Documenting inverse relation of serum cholesterol, the present study was structured to evaluate and correlate serum lipid levels among potentially malignant and oral cancer patients. An alternate hypothesis of inverse relationship of cholesterol and cancer was established.
A future analysis of lipid profile in greater number of oral cancer and potentially malignant disorders with longer follow up may further strengthen the hypothesis of inverse relation between oral cancer and serum lipid profile.

\section{References}

1. Greenberg MS, Glick M.Burket's Oral Medicine, Diagnosis and Treatment.10 ${ }^{\text {th }}$ edn.Elsevier India, 2003; 194-6.

2. Vidya KL, Shirish SD, Rahul RD, Ravindra PK, Suwarna BD. Evaluation of correlation of serum lipid profile in patients with oral cancer and precancer and its association with tobacco abuse. J Oral Pathol Med 2010; 39:141-8.

3. Sandeep A B, Navneet S e tal. Alterations in Serum Lipid Profile Patterns in Oral Cancer: Correlation with Histological Grading and Tobacco Abuse. OHDM: 2014; 13:573-79.

4. Mashberg A, SamitAM. Early detection, diagnosis, and management of oral and oropharyngeal cancer.CA Can J Clini 1989; 39:67-88.

5. Goyal S .Serum lipid profile in patients with oral tobacco habits and oral pre -cancer lesions and conditions. Webmed Centr Oral Med 2013; 4(2):6-10.

6. Sherubin EJ, Kannan KS, Kumar DN, Joseph I. Estimation of plasma lipids and its significance on histopathological grades in oral cancer. Prognostic significance an original research. J of Oral \& Maxillofac Patho 2013; 17(1):4-9.

7. Chawda JG, Jain SS, Patel HR, Chaduvula N, Patel K. The relationship between serum lipid levels and the risk of oral cancer. Indi J of Medi \& Paedia Onco 2011; 32(1):43-7.

8. Kumar P, Augustine J, Urs AB, Arora S, Gupta S, Mohanty VR. Serum lipid profile in oral cancer and leukoplakia: correlation with tobacco abuse and histological grading. J Can Res Ther 2012; 8:384-8.

9. Anuradha A, Veerathu LK, Sudhakar G, Kolla S , Sidhanathi N, Kond reddy R, Shakila S, and Peela JR. Lipid profile in oropharyngeal cancer in southern India .J of Can Res Updates 2013;2(1):99-104.

10. Patel PS, Shah MH, Jha FH.et al.Alteration in the plasma lipid profile in head and neck cancer and oral precancerous conditions. Indi J Canc 2004; 41:25-31.

11. Mehrotra R, Pandya S, Chaudhary AK, Singh HP, Jaiswal RK, Singh M, Gupta SC, Singh M. Lipid profile in oral submucous fibrosis, lipid in health and disease 2009, 8:29.

12. Lohe VK, Degwekar SS, Bhowate RR, Kadu RP, Dangore SB. Evaluation of correlation of serum lipid profile in patients with oral cancer and pre-cancer and its association with tobacco abuse. J Oral Patho Med 2010; 39:141-48.

13. Nayak P, Nayak S, Darafsh MD. Alteration in plasma lipid profile in precancerous conditions. Nepal Dent Assoc 2010; 11:40-56. 